\title{
OPEN Integrating spatial analysis and questionnaire survey to better understand human-onager conflict in Southern Iran
}

\author{
Alireza Mohammadi ${ }^{1 凶}$, Kamran Almasieh², Ho Yi Wan ${ }^{3}$, Danial Nayeri ${ }^{3}$, Amir Alambeigi ${ }^{4}$, \\ Jason I. Ransom ${ }^{5} \&$ Samuel A. Cushman ${ }^{6}$
}

Southern Iran is a conservation priority area for the endangered Persian onager (Equus hemionus onager), which is threatened by habitat fragmentation and conflict with local communities. To better understand factors that influence onager conservation, we administered a questionnaire in local communities to survey their ecological knowledge, personal experience related to onager, and attitudes toward traditional solutions for reducing crop damage by onager. In addition, we used resistant kernel and factorial least-cost path analyses to identify core areas and corridors for onager movement, and spatial randomization of vehicle collisions and crossing locations to test the predictive ability of resistant kernel and factorial least-cost path predictions of movement. We found that local communities that were knowledgeable about onagers experienced less crop damage from onager compared with those who used traditional methods. Habitat connectivity models revealed that core areas of movement are highly concentrated at the center of protected areas. Some sections of core areas have been cut off by roads where most vehicle collisions with onagers occurred. We propose that effective onager conservation will require integrated landscape-level management to reduce mortality risk, protection of core areas and corridors, development of mitigation strategies to reduce vehicle collisions, and conflict mediation between local communities and onagers.

The Persian Onager (Equus hemionus onager) is the only representative of order Perissodactyla in Iran. It is listed as endangered (EN) under the IUCN Red List and is considered the rarest living subspecies of Asiatic wild ass ${ }^{1,2}$. Onager populations in Iran are concentrated in two geographically separate areas: Bahram-e-Goor Protected Area and Touran Protected Area, located in the south and the central parts of Iran, respectively.

In Bahram-e-Goor Protected Area, population estimates in recent years suggest a positive trend ${ }^{2}$. However, there is concern that rising onager abundance may lead to vegetation degradation and water depletion problems ${ }^{3,4}$. Major threats to onager are conflicts resulting from crop-raiding, and road collisions occurring when onager cross roads to access crops $^{3,5}$, and grazing competition between herbivores and livestock ${ }^{6,7}$. Among these threats, agricultural crop-raiding is considered the most important conflict between human and onagers. High crop damage is associated with antagonism of local communities towards this species.

The study region is an arid environment where vegetation is unproductive and sparsely distributed ${ }^{5}$. During the dry summer (from June to August), there is little to no growth in most annual and perennial plants, and herbivores are subject to nutritional stress. Water is a major limiting resource for the onager in this season ${ }^{5,8,9}$. Increases in local onager abundance following better protection measures and management has resulted in onagers moving to agricultural lands which abut the protected areas in which their populations are concentrated during dry months. Such seasonal movement, coupled with an increasing onager population, results in intensified conflicts with the agro-pastoral community such as increasing crop-raiding incidences. Resolving these conflicts is a challenging task for wildlife and land managers ${ }^{10}$. Vehicle collisions pose another substantial threat

\footnotetext{
${ }^{1}$ Department of Environmental Science and Engineering, Faculty of Natural Resources, University of Jiroft, Jiroft, Iran. ${ }^{2}$ Department of Nature Engineering, Agricultural Sciences and Natural Resources University of Khuzestan, Mollasani, Iran. ${ }^{3}$ Department of Wildlife, Humboldt State University, 1 Harpst Street, Arcata, CA 95521, USA. ${ }^{4}$ Department of Agricultural Extension and Education, College of Agricultural Economics and Development, University of Tehran, Karaj, Iran. ${ }^{5}$ Department of Ecosystem Science and Sustainability, Colorado State University, Fort Collins, CO, USA. ${ }^{6}$ USDA Forest Service Rocky Mountain Research Station, 2500 S. Pine Knoll, Flagstaff, AZ, USA. ${ }^{\circledR}$ email: armohammadi1989@gmail.com
} 


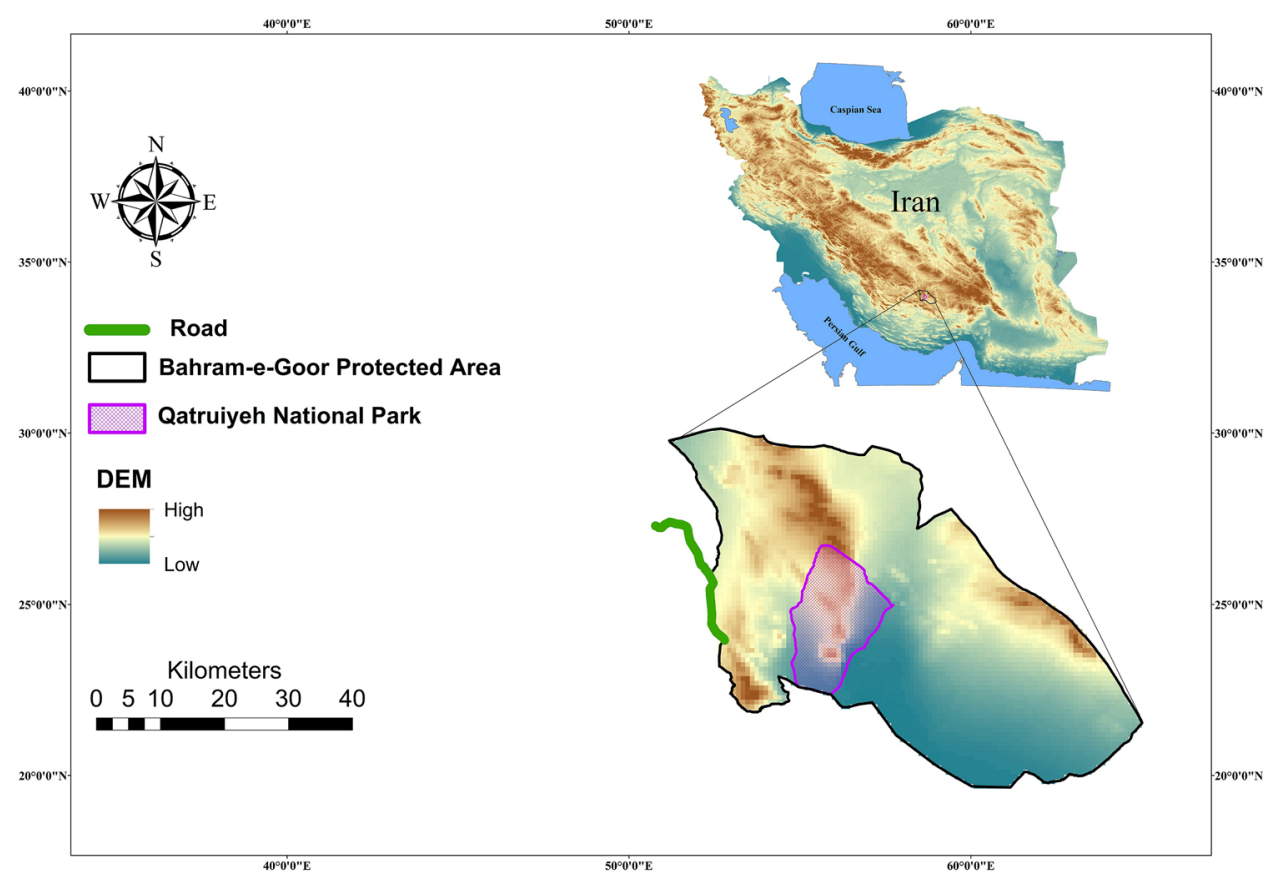

Figure 1. Location of the study area. The software ArcGIS. Version 10.2. was used to generate figure. DEM map was downloaded from the WorldClim database (http://www.worldclim.org).

to the onager population in Bahram-e-Goor Protected Area ${ }^{3}$. The Hassan Abad-Meshkaan road, which skirts the periphery of the area, has impacted the connectivity of the onager population and has become a source of mortality and hazard for both onagers and local communities.

Connectivity models provide practical tools for assessing potential fragmentation effects of roads on wildlife and can help and inform managers for management and conservation planning ${ }^{11,12}$. A wide variety of methods have been proposed for connectivity analysis, including least-cost path modelling ${ }^{13}$, current flow ${ }^{14}$, factorial least-cost path density ${ }^{15}$, resistant kernels ${ }^{16}$ and randomized shortest path algorithm ${ }^{17}$. The factorial least-cost path and cumulative resistant kernel approaches are particularly valuable when used in combination to accurately identify core habitats, fracture zones and corridors across a broad landscape ${ }^{18,19}$.

To support effective conservation and management of the onager population, this study focuses on understanding the drivers of, and mitigation options for, human-onager conflicts. Furthermore, identifying core habitats and movement corridors is essential to identify the locations of the road onager crossing concentrations and to develop comprehensive landscape-scale onager conservation plans. We hypothesized that (1) local people that were more knowledgeable about the ecological role of onagers experience less crop damage compared with those who are less knowledgeable and use traditional methods. (2) Roads are a major driver of human-onager conflicts because they coincide with core areas and corridors used by onagers.

\section{Materials and methods}

Study area. Qatruiyeh National Park, established in 2008, is a core zone in the Bahram-e-Goor Protected Area (established in 1972) at the border of Fars and Kerman provinces in southern Iran (Fig. 1). It covers 310 $\mathrm{km}^{2}$ and is part of the Zagros Mountains. It is a semi-desert with temperate arid climate, vegetated mainly with Zygophyllum eurypterum and Artemisia sieberi ${ }^{20}$. There are seven villages in the vicinity of the protected area, where pastoralism is the main source of livelihood ${ }^{21}$.

One of the major threats for the Persian onager populations in this area is increasing construction of new roads and increasing road traffic. The Sirjan-Yazd (Hassan Abad-Meshkaan) asphalt road, which passes through the Bahram-e-Goor Protected Area, was recently converted into a highway and represents a substantial threat to Onagers (Fig. 1). This road has two lanes in each direction. The day-time speed limit on this road is $110 \mathrm{~km} / \mathrm{h}$ and $90 \mathrm{~km} / \mathrm{h}$ at night. Most vehicles on this road are heavy trucks, which pass at high speed (more than $90 \mathrm{~km} / \mathrm{h}$ ), with high traffic volumes at night. During winter, late autumn and summer of drought years, when fodder is scarce, onagers frequently cross the road to access gardens and agricultural fields, which causes high onager mortality due to vehicle collisions. In this research, we used spatial randomization of vehicle collisions and crossing locations to test the predictive ability of resistant kernel and factorial least-cost path predictions of movement ${ }^{18}$. We also conducted questionnaires with residents from local communities to determine the most important factors influencing human-onager conflicts in the Bahram-e-Goor Protected Area.

Human-onager conflict assessment. Qualitative data collection. We administered a questionnaire through a personal interview to 200 randomly chosen farmers residing near onager populations in the Bahram- 
e-Goor Protected Area in Fars province. Data were collected through a questionnaire between May and August 2018 (Table S1). Ethical clearance was obtained from the DOE (under permit 32-239). All participants were given a printed descriptive summary of the research (if participants were illiterate, the document was read to them). Prior informed consent was obtained orally from all participants. In this research, we followed legal requirements of ethical issues.

We calculated the sample size needed by using the family size in rural areas around Bahram-e-Goor Protected Area using the Daniel method ${ }^{22}$ (Table S1) as described below (Eq. 1):

We randomly conducted 200 questionnaires in total.

$$
N=\frac{Z^{2} P(1-P)}{d^{2}}
$$

In this equation, $Z$ is the $Z$ statistic for a level of confidence, $P$ is expected prevalence or proportion (if the expected prevalence is $20 \%$, then $\mathrm{P}=0.2$ ), and $d$ is precision (if the precision is $5 \%$, then $\mathrm{d}=0.05$ ). In this research, we used $d=0.5$ and $p$ was selected according to family sizes in each district of rural areas ${ }^{22}$.

All interviewees were adult males. We collected information on interviewees' demographic and socioeconomic background (occupation, property, age, and income) as well as their knowledge and opinion on how to prevent onager crop-raiding.

We used logistic regression to analyze the significance of sociological factors related to crop damage by onagers. Our dependent variable was "Have you had any of your crop raided by onager during the last year? (Binary response: $1=$ Yes, $0=$ No)". Our independent variables included: (1) traditional solutions for reducing Persian onager damages (Response: 1 guarding dogs, 2: fencing around agricultural land, 3: use of traditional barriers (a plastic cuff with a bell on it), 4: scarecrow, 5: turn on the lights at night , 6: Bird-Scarer (Kalaghparan in Persian); (2) which of these solutions could be effective in reducing Persian onager damages (Responses included: 1: fencing around Persian onager habitat, 2: fencing around farmland, 3: give fodder and provide water for Persian onager, 4: buying fodder from local people by DoE, 4: capturing and relocating Persian onager); (3): do you agree with Persian onager hunting? (Binary response: $1=$ Yes, $0=$ No); (4): what is the role of the Persian onager in the wild? (Response 1: distributing seed of plants, the rangelands are restored, 2: it attracts tourists in the region, 3: beauty of nature: God's creature with a right to live (Intrinsic value), 4: none) (5): age (response: $1:<30$ Years, 2: 30-50 Years, 3: $>50$ Years), (6): education (response: 1: Incomplete Elementary (lower than 5th grade of elementary), 2: Complete Elementary (5th grade of elementary), 3: Incomplete High school, 4: Associate Degree, 5: Bachelor of Science (BSc), 5: Master of Science (MSc) or Higher), (7) Experience of Persian onager observation in nature: Have you ever seen a Persian onager in the wild? (Response scale: 1 = Yes, frequently, $2=$ Yes, several times, 3: Yes, a few times 4: No, never, 5: only seen the Asiatic wild ass carcass), (8) the presence of a Persian onager around your village damages your farms and gardens. How do you feel about this statement? (Response scale) 1: completely disagree, 2: Somewhat disagree, 3: I do not agree or disagree, 4: I agree somewhat, 5: completely agree.

All statistical tests were conducted in IBM SPSS Statistics (V. 23.0). Independent variables in the logistic regression analysis were coded as showed in Table S1.

Naïve Bayes classification. Naïve Bayes Classification uses a group of simple classifiers based on probabilities, which are applicable to the types of random independent variables in our study. This approach is a supervised machine learning algorithm based on the Bayes Theorem that is used to solve classification problems by following a probabilistic approach. We used the e 1071 library ${ }^{23}$ in $\mathrm{R}$ version $3.5 .3^{24}$ for Naïve Bayes classification of onager crop-raiding under this scheme. We considered: Yes (local communities with experience of cropraid damages), or No (local communities without experience of crop-raid damages during the last one year) as a dependent variable, as a function of the independent variables described in logistic regression section, except we also included farm land area $(1:<1 \mathrm{ha}, 2: 1-5 \mathrm{ha},>5 \mathrm{ha})$ as an additional variable.

We categorized data into two groups (testing and training) to determine whether the model performed correctly based on training data. Subsequently, $70 \%$ of the data were used to test and run the model along with training confirmation. The Naïve Bayes Classifier was trained to anticipate each attitude in the test data. We calculated the randomness of our results using the Mclust library ${ }^{25}$ in R version 3.5. $3^{24}$.

Onager vehicle collisions. A 25-km section of the 99-km Hassan Abad-Meshkaan road (the area with the highest wildlife-vehicle collision reports) was monitored by motorcycling and walking daily from August to October 2017 (3 weeks). Every morning, we inspected for mammal roadkill within a 30-m buffer on each side of the road, and all carcasses of mammals were recorded using a handheld GPS (Garmin GPS Map 62S). To avoid double-counting, we removed the carcasses after recording. We also obtained collision location data during 2004-2018 from the DoE.

The crossing data for onager were obtained from a variety of sources including opportunistic direct observation, environmental guard's information, and monitoring by LED portable flashlight at night (summer and autumn seasons of 2017 and 2018).

Habitat connectivity analysis. Habitat suitability modeling. A total of 103 presence points were obtained from DoE (2015) in the study area, including Bahram-e-Goor Protected Area, as well as nearby surroundings. To minimize spatial autocorrelation, a $1-\mathrm{km}$ radius was used to eliminate points around each presence location using the SDM toolbox ${ }^{26}$. The remaining 90 presence points were used in the modeling. 


\begin{tabular}{|l|l|l|l|}
\hline Category & Variables & Unit & Source \\
\hline \multirow{2}{*}{ Topography } & Elevation & Meter & https://glovis.usgs.gov \\
\cline { 2 - 4 } & Slope & Percentage & Elevation \\
\hline \multirow{2}{*}{ Food and cover } & Land-cover & Class & FRWMO, 2010 \\
\cline { 2 - 4 } & Distance from agricultural lands & Degree & Land-cover \\
\hline \multirow{2}{*}{ Human disturbance } & Distance from road & Degree & DoE, 2018 \\
\cline { 2 - 4 } & Distance from villages & Degree & DoE, 2018 \\
\hline
\end{tabular}

Table 1. Environmental variables used for habitat modeling of the Persian onager in the study area.

A habitat suitability map for onager was developed using MaxEnt software version $3.3 .3 \mathrm{k}^{27}$ to create a resistance map for connectivity modeling ${ }^{28}$. We used 10,000 pseudo-absence points ${ }^{29}$. For the training data set, $75 \%$ of the presence points were randomly chosen to train and the remaining $25 \%$ were used to test the model ${ }^{30}$. We used the area under the ROC curve (AUC) to evaluate model performance. MaxEnt models were completed with 10 bootstrapped replicates.

Environmental layers included in MaxEnt modeling included (1) elevation (digital elevation model [DEM]), (2) slope, (3) land cover, (4) distance from agricultural lands, (5) distance from roads and (6) distance from villages. All layers had a $30 \mathrm{~m} \times 30 \mathrm{~m}$ resolution (Table 1 ).

Slope was calculated from the DEM layer. Land cover for 27 vegetation classes in the study area was reclassified to 10 classes based on similarities between classes in the original landcover map and due to the importance of agricultural lands (5\% of the study area) to onagers. Distance from agricultural lands, roads and villages were included as predictor variables, and were calculated with the Euclidean distance tool in the Spatial Analyst extension of ArcGIS 10.2. We checked for multi-collinearity among variables and correlation was $<|0.7|$ between all pairs of variables. In addition, multi-collinearity among variables was further examined using USDM ${ }^{31}$ pack- $^{-}$ age version $3.5 .3^{24}$ and variables with VIF (variance inflation factor) $>3$ were used as a threshold to exclude variables $^{32}$. VIF ranged from 1.2 to 1.8 for all variables. Therefore, all variables were retained for habitat modeling.

Resistance surface for connectivity analysis. To estimate landscape resistance, we converted the habitat suitability maps to resistance maps using a negative exponential function $\left(\mathrm{R}=1000^{(-1 \times \mathrm{HS})}\right)$ where $\mathrm{R}$ represents the cost resistance value assigned to each pixel and HS represents the predicted habitat suitability derived from the suitability models described above ${ }^{33}$. We used 1000 as the base of our exponential decay function such that areas with $>0.3$ habitat suitability would have low-cost resistance. We rescaled the resistance values to a range between 1 and 100 by linear interpolation, such that minimum resistance (Rmin) was 1 when HS was 1 , and maximum resistance (Rmax) was 100 when HS was $0^{33}$.

Connectivity corridor network simulation. We used the universal corridor network simulator (UNI$\mathrm{COR})^{34}$ to predict movement core areas and corridors for Onagers. UNICOR's key features include a drivermodule framework, connectivity mapping with thresholding and buffering, and graph theory metrics. UNICOR produces two kinds of connectivity predictions: (1) resistant kernels ${ }^{16}$ and (2) factorial least-cost paths ${ }^{15}$. The factorial least-cost path analysis implanted in UNICOR simulator uses Dijkstra's algorithm ${ }^{34}$ to solve the singlesource shortest path problem from every mapped species occurrence location on a landscape to every other occurrence location $^{34}$. The analysis produces predicted least-cost path routes from each source point to each destination point. The resistant kernel algorithm calculates the resistance cost weighted dispersal kernel around each source point up to a user-defined dispersal threshold, and then sums these, producing an incidence function of the rate of organism movement through every pixel in the landscape as a function of the number and density of source points, the dispersal ability of the species, and the resistance of the landscape.

According to observation and reports of experts in the DoE, the maximum dispersal of threshold for movement of Onagers is about $100 \mathrm{~km}$. We thus specified a dispersal threshold of 100,000 cost units for the resistant kernel analysis ${ }^{35}$. We calculated the factorial least-cost path network without dispersal the threshold ${ }^{35}$ to provide a broad-scale assessment of the regional pattern of potential linkage and to map corridors. The buffered least-cost paths were then combined through summation ${ }^{15}$ to produce maps of connectivity among all pairs of presence points.

Evaluating congruence between crossing points and predicted connectivity. We used a spatial randomization testing procedure to evaluate congruence between the locations where onagers were observed crossing the road and resistant kernel values of predicted connectivity ${ }^{18}$. Spatial randomization testing of this kind is recommended in cases where there is spatial dependence among observations, and produces an unbiased estimate of the probability of the observed outcome given the data ${ }^{18}$.

We compared the median value of predicted connectivity (resistant kernel) for the 104 actual onager crossing locations with the distribution of median values of $1 \times 10^{7}$ random samples of 104 locations along the highway within the study area. For each combination of resistance surface and connectivity modeling approach, we calculated the ranking of the median of observed values within the distribution of the medians of the $1 \times 10^{7}$ random samples. 

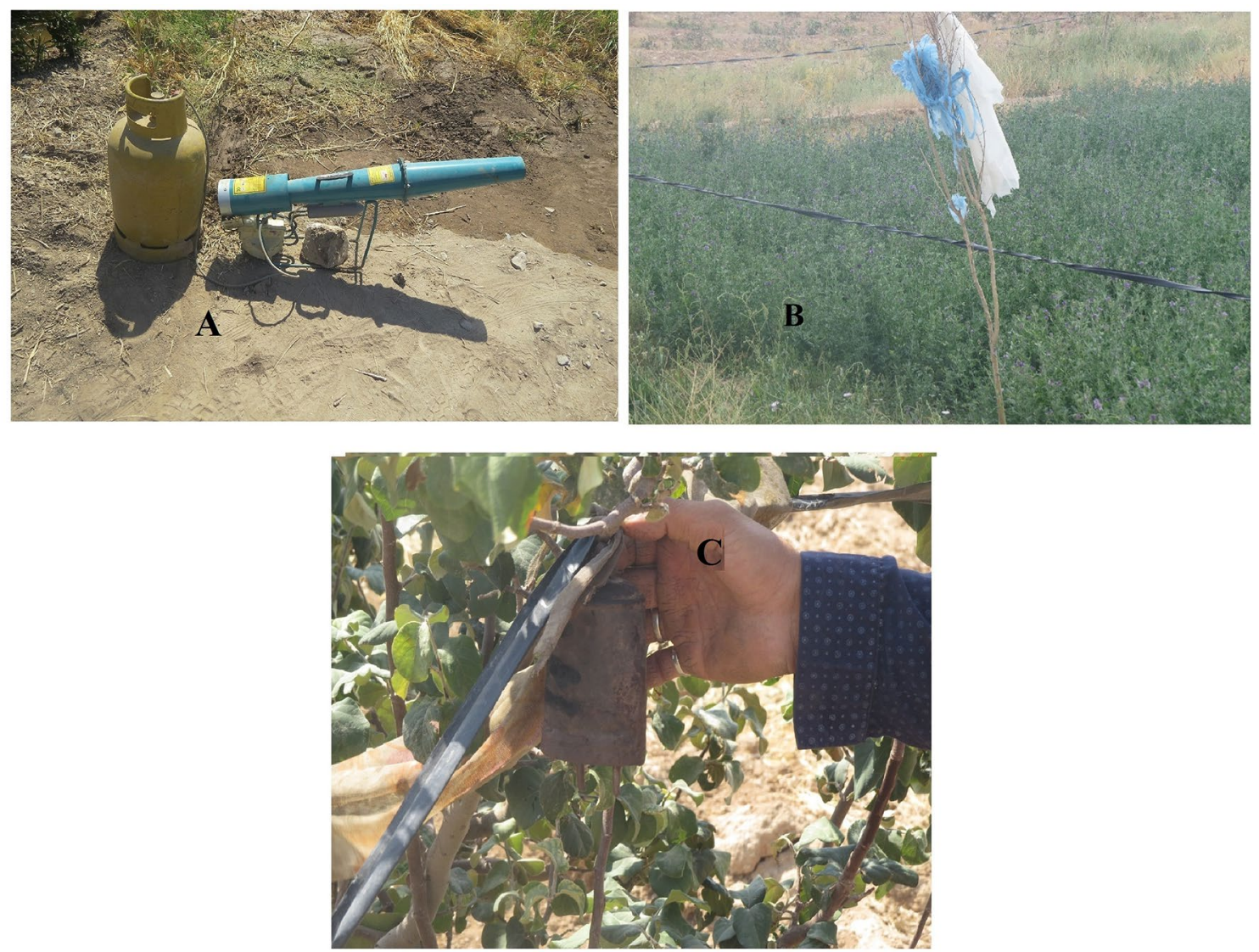

Figure 2. Traditional methods (A: Bird-Scarer (kalaghparan in Persian) B: Fencing use a plastic cuff and C: A plastic cuff with a bell on it) used by local communities for reducing HOC. Photo by Danial Nayeri and Alireza Mohammadi. Canon SX50 HS was used.

\section{Results}

Interviewees. Respondents were on average 45.5 years old (range $=20-80$ years, median $=44$ years $\mathrm{SE}=0.26) .87 \%$ were farmers and ranchers, $6.3 \%$ were only farmers, $6.7 \%$ were ranchers. Most of the respondents (92.8\%) owned agricultural lands, and $56.5 \%$ of their economic income was strongly dependent on agricultural lands. Local communities had an average of 2.5 ha of crop lands.

The majority of respondents had observed onager in the wild (88.5\%), and 55\% reported experiencing onager crop damage. Most people believed that the presence of onager around their village lead to crop damage (87.1\%).

The majority of local people (59\%) agreed with fencing around onager habitat, fencing their agricultural lands (95\%), providing fodder and water for the onager (85.5\%), buying fodder from local people by DoE (89.5\%), and capturing and relocating the onager (71\%). Most local people thought that guarding dogs (91\%), scarecrow (99.5\%), turning the lights on at night (97\%) and deterrents such as terrifying sound machine and bird-scarers (57.5\%; Fig. 2) were ineffective methods for mitigating onager crop damages. In contrast, fencing (96.5\%) and using traditional barriers such as plastic cuff with a bell on it (61\%) were considered effective methods to mitigate human-onager conflict.

Over half of the surveyed locals have experienced crop damage by onagers during the summer season (63\%). Alfalfa (55\%), barley (35\%), and wheat (10\%) were reported as the most susceptible crops to damage by onagers in this region. Most locals believed that drought and the lack of available forage in the wildlands are the main reasons for onagers approach the villages $(98 \%)$. Only $2 \%$ of the local communities consider water scarcity as the main reason for the proximity of onagers to the villages.

We found that $25 \%$ of the respondents believe that onagers have no role in nature, and only $6 \%$ were knowledgeable of the ecological role of onagers and believed that the species disperses seeds and restores rangelands. Also, $7.5 \%$ of the respondents thought that onagers attracted tourists, $29.5 \%$ believe that Onagers are God's creation with intrinsic value, and $32 \%$ consider onagers to contribute to the beauty of nature.

Only $29.5 \%$ of the locals believe that onagers should be strictly conserved. $30 \%$ of the locals believe that the number of this species has increased but has caused tolerable damage with no significant conflict, and $36.5 \%$ of local people believe that their number has increased but also believe that decreasing onagers through hunting can mitigate human-onager conflict. Finally, $4 \%$ of local people believe that damages caused by onagers are intolerable and support immediate removal of the species from the region. 


\begin{tabular}{|c|c|c|c|c|c|c|c|c|}
\hline \multirow[b]{2}{*}{ Variable } & \multirow[b]{2}{*}{ B } & \multirow[b]{2}{*}{ S.E } & \multirow[b]{2}{*}{ Wald } & \multirow[b]{2}{*}{ df } & \multirow[b]{2}{*}{ Sig } & \multirow[b]{2}{*}{$\operatorname{Exp}(B)$} & \multicolumn{2}{|c|}{$\begin{array}{l}\text { 95\% C.I.for EXP } \\
\text { (B) }\end{array}$} \\
\hline & & & & & & & Lower & Upper \\
\hline $\begin{array}{l}\text { Do you Agree with Persian onager hunting? } \\
\text { Yes }\end{array}$ & 1.159 & 0.819 & 2.004 & 1 & 0.157 & 1.186 & 0.640 & 1.100 \\
\hline No & 1.130 & 0.620 & 1.200 & 1 & 0.250 & 1.110 & 0.800 & 0.995 \\
\hline \multicolumn{9}{|l|}{ Knowledge: What is the role of the Persian onager in the wild? } \\
\hline 1: By distributing seed of plants, the rangelands are restored & 0.346 & 0.110 & 6.210 & 1 & 0.012 & 1.230 & 1.070 & 2.010 \\
\hline 2: It attracts tourists in the region & 0.510 & 0.560 & 7.200 & 1 & 0.041 & 1.230 & 1.070 & 2.010 \\
\hline 3: Beauty of nature & 0.600 & 0.210 & 6.150 & 1 & 0.004 & 1.05 & 1.070 & 1.900 \\
\hline 4: God's creature with a right to life & 0.065 & .082 & 0.639 & 1 & 0.424 & 1.068 & 0.909 & 1.253 \\
\hline 5: None & -0.013 & .237 & 0.003 & 1 & 0.957 & 0.987 & 0.621 & 1.570 \\
\hline \multicolumn{9}{|c|}{ Which of these solutions could be effective in reducing Persian onager damages? } \\
\hline 1: Fencing around the onager habitat & -0.036 & 0.128 & 0.082 & 1 & 0.775 & 0.964 & 0.751 & 1.238 \\
\hline 2: fencing around farmland & 0.052 & .0207 & 0.062 & 1 & 0.803 & 1.053 & 0.702 & 1.578 \\
\hline 3: Give fodder and provide water for Persian onager & 0.489 & .0302 & 2.624 & 1 & 0.105 & 1.631 & 0.902 & 2.949 \\
\hline 4: buying fodder from local people by DOE & -0.787 & .0538 & 2.140 & 1 & 0.143 & 0.455 & 0.159 & 1.306 \\
\hline 5: capturing and relocating Persian onager & -0.629 & 0.751 & 0.701 & 1 & 0.402 & 0.533 & 0.122 & 2.323 \\
\hline Education & -0.009 & 0.210 & 0.002 & 1 & 0.964 & 0.991 & 0.656 & 1.495 \\
\hline Age & -0.010 & 0.020 & 0.233 & 1 & 0.630 & 0.990 & 0.952 & 1.030 \\
\hline $\begin{array}{l}\text { Traditional Solution for reducing Persian onager damages: } \\
\text { 1: Guarding dogs }\end{array}$ & -.629 & .751 & .701 & 1 & 0.402 & .533 & .122 & 2.323 \\
\hline 2: Fencing around agriculture land & 1.280 & 1.657 & 4.322 & 1 & 0.384 & 0.635 & 0.289 & 1.821 \\
\hline 3: Use of traditional barriers (a plastic cuff with a bell on it) & -3.445 & .912 & 0.756 & 1 & 0.238 & 0.032 & 0.001 & 0.821 \\
\hline 4: Scarecrow & 2.622 & 1.524 & 2.960 & 1 & 0.005 & .073 & .004 & 1.440 \\
\hline 5: Turn on the lights at night & -1.979 & 1.829 & 1.170 & 1 & 0.279 & .138 & .004 & 4.989 \\
\hline 6: Bird-Scarer (kalaghparan In Persian) & 1.876 & 1.117 & 2.817 & 1 & 0.009 & 6.524 & .730 & 58.309 \\
\hline \multicolumn{9}{|l|}{ Experience of Persian onager observation in nature } \\
\hline $1=$ Yes frequently & -1.014 & 1.194 & 0.721 & 1 & 0.396 & 0.363 & 0.035 & 3.767 \\
\hline $2=$ Yes, several times & -0.781 & 0.566 & 1.902 & 1 & 0.168 & 0.458 & 0.151 & 1.389 \\
\hline 3: Yes, a few times & 1.925 & 1.032 & 3.477 & 1 & 0.062 & 6.853 & 0.906 & 51.816 \\
\hline 4: No, never & -0.074 & 0.830 & 0.008 & 1 & 0.929 & 0.929 & 0.183 & 4.723 \\
\hline 5: only seen the Persian onager carcass & -0.070 & 0.282 & 0.061 & 1 & 0.805 & 0.933 & 0.536 & 1.622 \\
\hline \multicolumn{9}{|c|}{ The presence of an Persian onager around your village damages your farms and gardens } \\
\hline 1: Completely disagree & 0.101 & 0.257 & 0.153 & 1 & 0.695 & 1.106 & 0.668 & 1.830 \\
\hline 2: Somewhat disagree & 0.173 & 0.401 & 0.187 & 1 & 0.665 & 1.189 & 0.542 & 2.609 \\
\hline 3: I do not agree or disagree & -0.008 & 0.217 & 0.001 & 1 & 0.972 & .992 & 0.648 & 1.519 \\
\hline 4: I agree somewhat & -0.783 & 0.956 & 0.672 & 1 & 0.412 & 0.457 & 0.070 & 2.973 \\
\hline 5: Completely agree & -0.002 & 0.174 & 0.000 & 1 & 0.992 & .998 & 0.710 & 1.403 \\
\hline Constant & 1.298 & 1.750 & 0.550 & 1 & 0.458 & 0.273 & - & - \\
\hline
\end{tabular}

Table 2. Logit function coefficient of Factors influencing Persian Onager crop damages (Ln ( $\mathrm{p} /$ $(1-\mathrm{p})=1.298+0.346(\mathrm{X} 1)+0.510(\mathrm{X} 2)+0.600(\mathrm{X} 3)+2.622(\mathrm{X} 4) 1.876(\mathrm{X} 5))$.

Factors influencing Persian onager crop damages. Our omnibus tests of model coefficients were significant $\left(\chi^{2}=35.759, \mathrm{df}=16, \mathrm{P}=0.03\right)$, with goodness of fit $=140.109$ for -2 Log-likelihood, and Nagelkerke $\mathrm{R}^{2}=0.280$. Cox and Snell $\mathrm{R}^{2}$ was 0.164 . The prediction accuracy of the model was $84.5 \%$. In this analysis, the two significant variables were knowledge and local communities that used traditional methods for mitigating onager crop damages. We found that communities that were knowledgeable regarding the role of onagers (local people who believed: (1) by distributing seed of plants, the rangelands are restored, (2) onagers attract tourists in the region, and (3) onagers were part of the beauty of nature were less subject to crop damage by onagers (Table 2). Those who used traditional methods for mitigating onager crop damages (i.e., scarecrow and bird-scarer) were more prone to onager crop damage.

Classification of local communities by onager-caused crop damage. The Naiive Bayes algorithm was able to classify 192 out of 200 "No" cases (local communities who have no experience of crop-raiding damages) correctly and 188 out of 200 "Yes" cases (local communities have experience of crop-raiding damages) correctly. Thus the Naïve Bayes algorithm has $96 \%$ success in predicting the "No" group is about $96 \%$ and $94 \%$ success in predicting the "Yes" group.

Our results showed that the most significant variables for predicting onager crop-raiding were farmland area, the opinion of onager as a serious threat to agricultural lands, and local communities who used traditional 


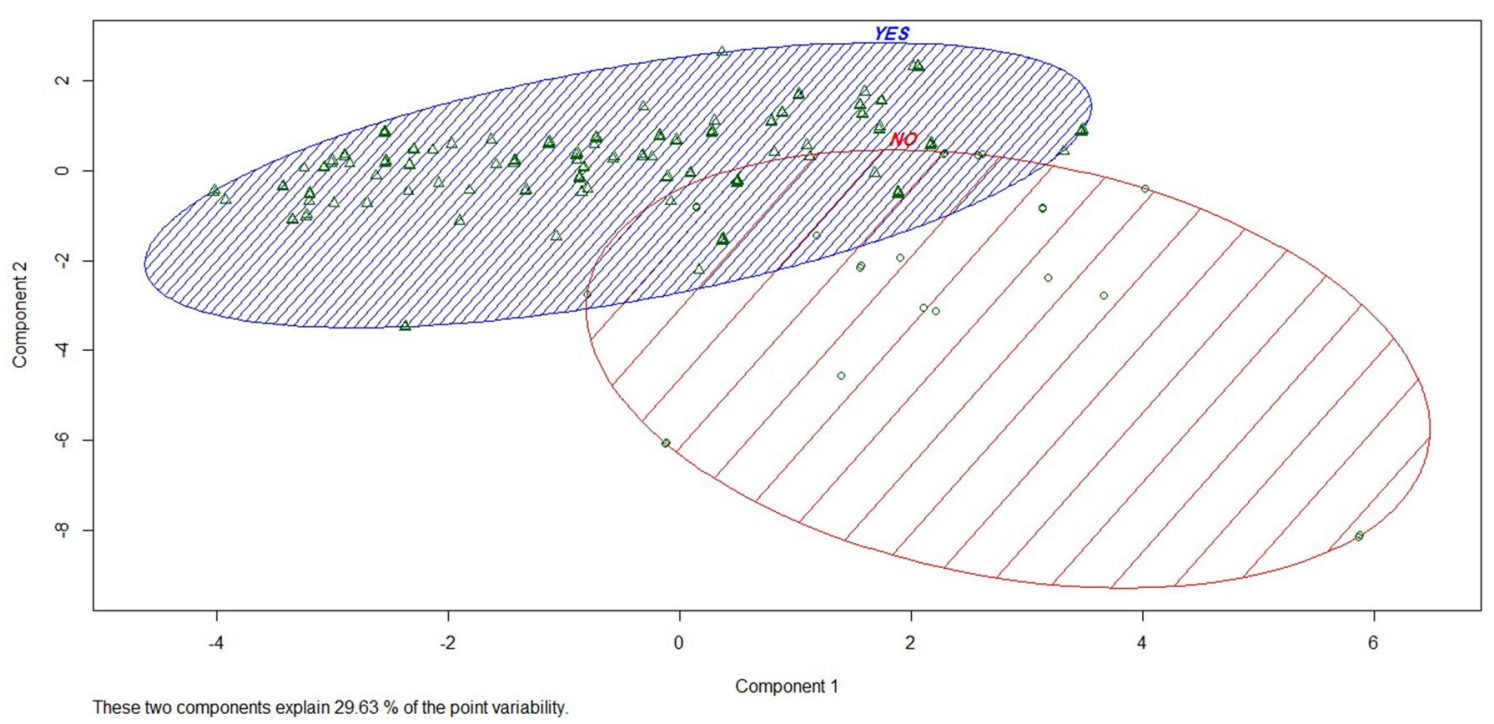

Figure 3. Classification of local communities using Naïve Bayes Classification according to damage or no damage of Persian Onager to agricultural products. In this figure the blue circle showed Yes group (local communities has experience of crop-raiding damages) and red circle showed No group (local communities who has no experience of crop-raiding damages). Triangles showed distribution of individual in Yes group and circles showed distribution of individual in No group.

methods. Our model supported that: (1) local respondents with more agricultural lands were more subject to onager damage, (2) local respondents who agree that onagers are a significant threat are more subject to crop damage, and (3) local respondents who use traditional methods such as scarecrow and bird-scarer to exclude onagers were more subject to onager damages (Fig. 3).

Habitat conectivity. Our MaxEnt model predictig Onager occurrence locations was highly predictive $(\mathrm{AUC}=0.89)$. Our connectivity simulation modeling revealed that high connectivity areas are in the southern parts of the Qatrouyeh National Park and in the western parts of the Bahram-e-Goor Protected Area. Also, connectivity extends through the west side of the protected area (Figs. 4 and 5).

Spatial randomization test. We found that 14 onagers were killed on the Hassan Abad-Meshkaan road during 2004-2018 (Table 3). Most onager road kills occurred in the summer season (Table 3). Most of the onagers that collided with vehicles were female (Table 3).

Our connectivity model strongly predicted onager highway crossing locations. Specifically, crossing locations have a much higher connectivity score than the distribution of randomized locations (Fig. 6). The median predicted connectivity value of 10,000 random points on the road was 22 , compared to a median connectivity value of 40 for the 104 onager crossing points considered in our analysis. The highest observed connectivity value of actual crossing points (104 points) was 49 , which is higher than the highest value among the random points $(10,000)$, which was 30 . Based on the randomization test the probability of the observed value being no different than the random value is $<0.00001$.

\section{Discussion}

Studies combining social sciences with habitat connectivity are scant globally ${ }^{36}$. Moreover, there has been little research about human-onager conflict in the study area ${ }^{37}$ despite its holding one of the largest remaining populations of Persian onager and also being an area of particularly high human-onager conflict. Hence, our study is one of the first studies that integrated spatial ecology of an endangered species with its human dimensions to facilitate sustainable coexistence. Furthermore, it is a fundamental first step to understanding the sociological and ecological drivers of conflict and identifying solutions to mitigate it. In general, we believe there is high value in assessing the knowledge and attitudes of the local people regarding onager, crop damage, and the best ways to mitigate it. Understanding the nature of human-wildlife conflict, and seeking means to resolve it, requires quantitative information about both the attitudes of people and the ecology and behavior of the wildlife species involved $^{38}$.Understanding that attitudes of local people coexisting with onagers is essential to effectively solve conflict problems. In addition, knowing the traditional methods used by local people to mitigate conflict and their applicability can aid managers to develop cost-effective solutions.

Minimizing onager crop-raiding. Food availability is a critical factor in onager conflict risk (Table 4). Scarcity of natural forage during drought conditions leads to onagers crossing roads and entering agricultural fields $^{39}$ (Table 4). In similar systems, crop-raiding conflicts involving the khur subspecies (E. h. khur), for exam- 


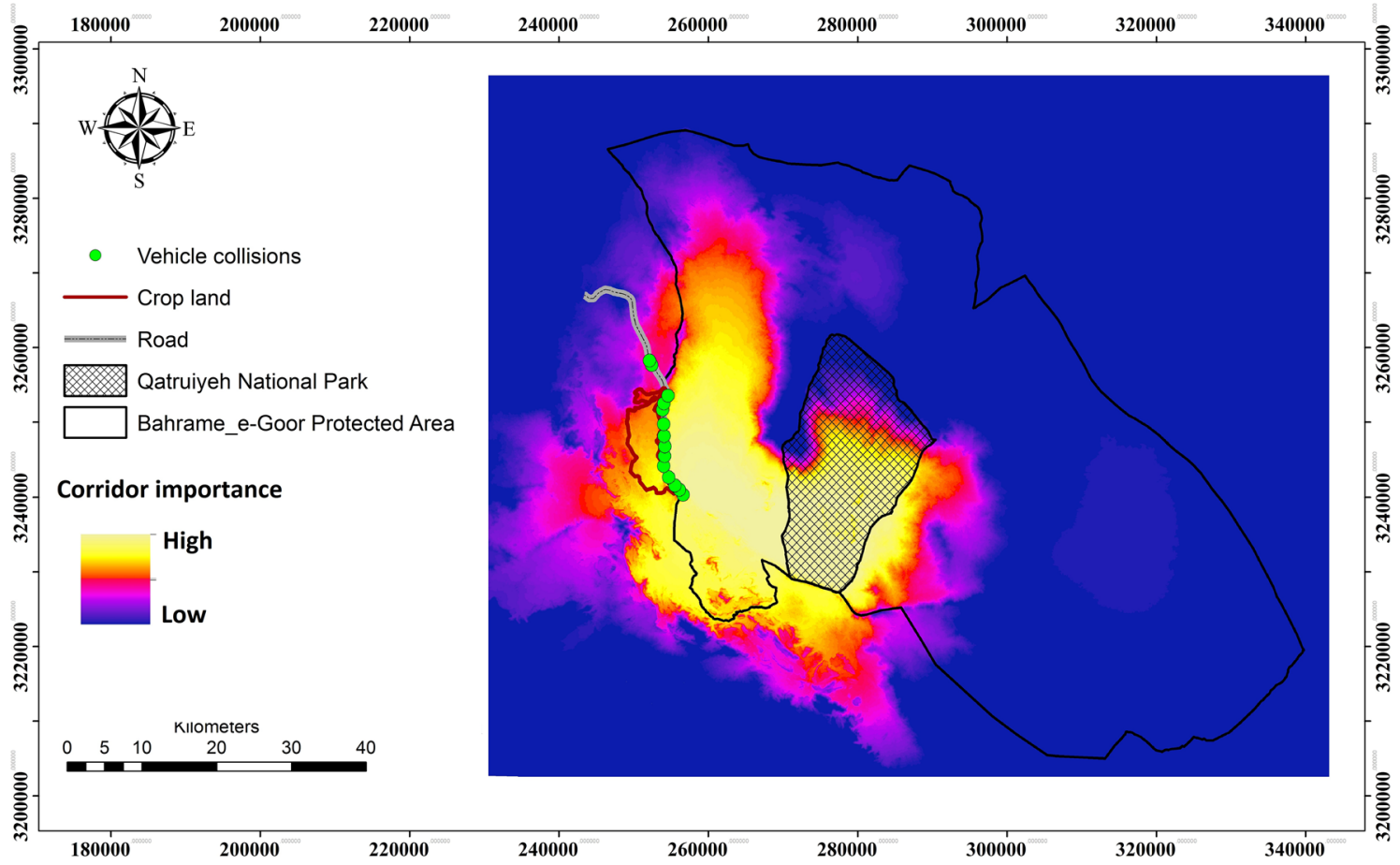

Figure 4. Resistant kernel core habitat areas (bright spot) for The Persian Onager in Bahram-e- Goor Protected Area in Iran. Connectivity models revealed that core areas of movement are highly concentrated at the center of protected areas. UNICOR (https://www.fs.usda.gov/treesearch/pubs/40686) software was used to generate the figure.

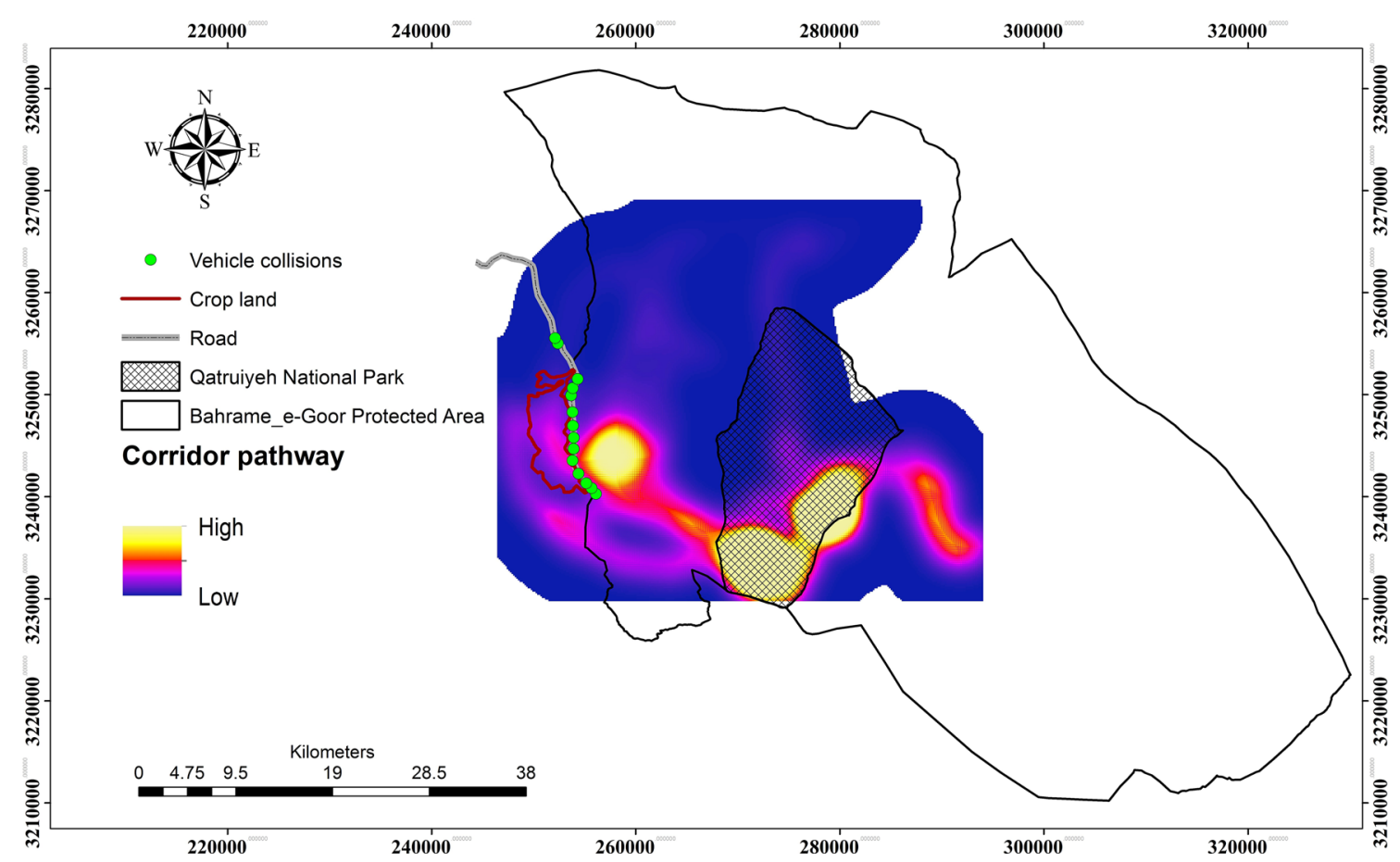

Figure 5. UNICOR corridor pathways for The Persian Onager in Bahram-e- Goor Protected Area in Iran. UNICOR (https://www.fs.usda.gov/treesearch/pubs/40686) software was used to generate the figure. 


\begin{tabular}{|l|l|l|}
\hline Year & Sex & Season \\
\hline 2004 & Female & April \\
\hline 2004 & Unknown & August \\
\hline 2006 & Male & August \\
\hline 2007 & Female & August \\
\hline 2008 & Male & August \\
\hline 2009 & Male & August \\
\hline 2011 & Female & August \\
\hline 2017 & Female & December \\
\hline 2017 & Female & December \\
\hline 2017 & Female & August \\
\hline 2017 & Male & April \\
\hline 2017 & Male & May \\
\hline 2018 & Female (Pregnant) & April \\
\hline 2018 & Female (Pregnant) & April \\
\hline
\end{tabular}

Table 3. Road mortalities of the Persian onager during 2004-2018.

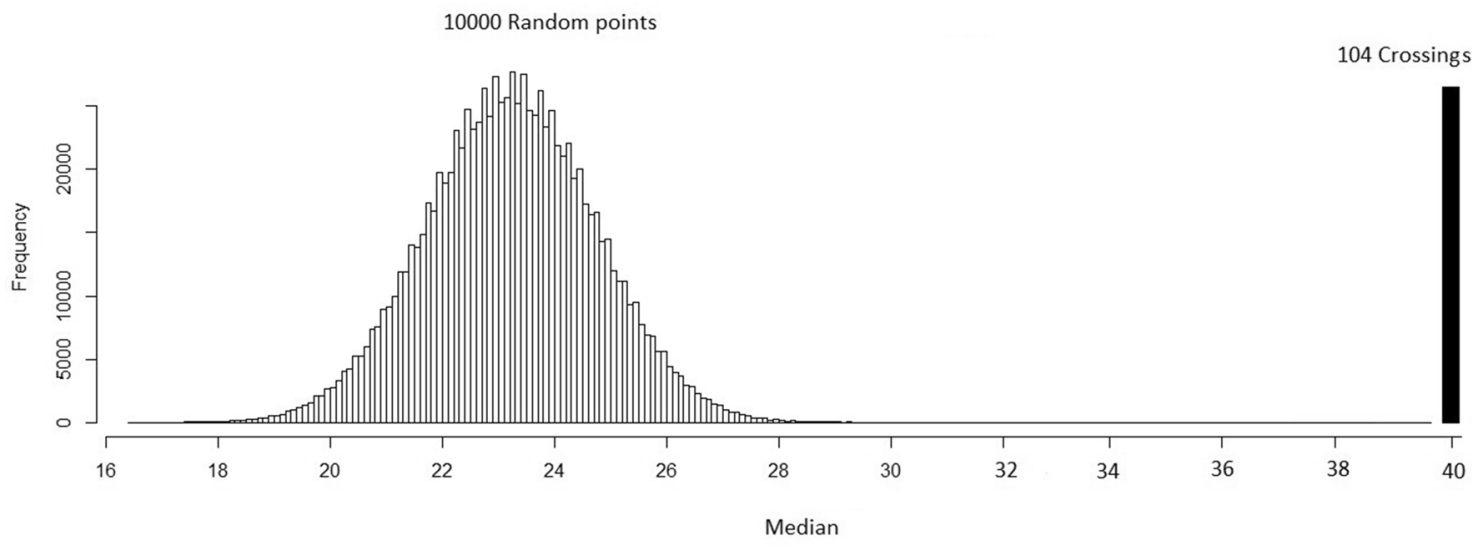

Figure 6. Spatial randomization test: the crossings have a much higher connectivity score than the randomization. Solid vertical line shows the median of 104 crossing locations. Tiny bars shows 10,000 random points. This means that connectivity model predicted Onager highway crossing locations precisely.

\begin{tabular}{|c|c|c|}
\hline Driving forces & Threats & Recommendations \\
\hline Reduced food availability and water during drought season & Increasing conflicts and road vehicle collisions & $\begin{array}{l}\text { (1) Increasing public awareness and educational programs } \\
\text { (2) Building artificial water ponds and supplying hay in areas away } \\
\text { from Agricultural lands } \\
\text { (3) Insurance scheme for agricultural lands } \\
\text { (4) Improving road safety for drivers and onagers }\end{array}$ \\
\hline
\end{tabular}

Table 4. Driving forces, threats and recommendations for human-onager conflicts in southern Iran.

ple, have recently increased because of natural dispersal of increasing populations into adjacent agricultural landscapes ${ }^{10}$. In contrast to findings from Esmaeili et al. $(2019)^{37}$, human-wildlife conflicts in our study area are relatively high (in comparison to past years), especially during dry summers and cold winters when forage is scarce. At such times onagers are forced to leave the protected areas and enter neighboring agricultural lands looking for food. Our results show that crop-raids by onagers and vehicle collisions both increase during these times (Table 4). Fences for excluding onagers from crops have been proposed as a solution. However, installing fences that can cover the entire study area is costly and impractical without financial subsidies from the government.

Increasing public awareness and educational programs may be a potential solution to human-onager conflicts. Our study shows that local respondents who are aware of the issues around onagers are less subject to crop damages compared with those who only use traditional tactics (e.g., scarecrow, guarding dogs, turn on lights at night and other deterrents) for mitigating crop damages. Our results confirmed our first hypothesis that 
people who are knowledgeable of the ecological role onager play in the ecosystem are less likely to experience crop damage. Our study is not able to separate causes versus correlations regarding attitudes of people toward onager. However, our results suggest that increasing the ecological knowledge of the local people about this species can help to promote co-existence and potentially reduce onager-crop damage. Most of the local people have a respectful attitude toward onagers and consider them as a natural heritage of their homeland, leading to support for onager conservation ${ }^{40}$.

Conservation actions such as building artificial water ponds and supplying hay in areas away from agricultural lands may reduce chances of onagers from entering local farms $\mathrm{s}^{4}$. These approaches are likely to be more financially feasible than installing fences over a large area. We also suggest that future studies examine alternative livelihoods and modifying crop cultivation for reducing human-wildlife interaction in this area.

Minimizing onager vehicle collisions. While crop-raiding is a primary nexus in human-onager conflict, the major threat for safe movement of onagers within their habitats is road crossing east-west through the landscape. Our corridor modeling demonstrated that the road on the western border of Bahram-e-Goor Protected Area had high impacts on onager movement, and this area has a concentration of onager-vehicle collisions. Roads were predicted to substantially reduce connectivity of onagers, which confirms our second hypothesis. Further, a large portion of onager mortality in the study region was related to road kills. Previous studies also suggest that roads are a predominant threat to animals due to road collisions and fragmentation of habitat ${ }^{41,42}$.

Mitigation measures to safeguard movement and road crossing of onager individuals should be considered in this area, particularly along the corridor routes we identified and validated with spatial randomization testing (Table 4). Our analysis confirmed that actual onager crossing locations were highly nonrandom, and closely associated with our predicted corridor locations. This is similar to the results of Cushman et al. ${ }^{18}$ for American black bear, and of Mohammadi et al. (in press) for grey wolf and jackal in Iran, suggesting that synoptic connectivity methods, such as resistant kernel and factorial least cost paths, are effective in predicting and prioritizing highway locations for mitigation ${ }^{43}$.

Although some parts of the border of the protected area were fenced along the road (south of the Bahrame-Goor Protected Area), some parts of the fence have been destroyed, and onagers cross the road and enter the villages at night and damage crops. Such movements not only intensify the risk of vehicle collisions but also generate problems for local livelihoods by raiding crops and trampling. We thus suggest rebuilding and expanding the fences in strategic locations that provide a barrier between onager habitat and crops, or in places that actively funnel movement of onagers between habitat patches and around agricultural areas. Provision of more waterholes in the outlying areas may also mitigate the need for onagers to visit village ponds or irrigation tanks, and may help keep onagers away from croplands.

The DoE has designed and prepared eight onager warning signs, for increasing public awareness. We recommend installing these signs at the crossing locations highlighted in our connectivity analysis. Persian onager mortality rates and critical locations should be assessed before installation of the signs to help optimally locate them and enable subsequent measurement of their effectiveness in the reduction of onager collision. Most studies on the effectiveness of signs in reducing WVCs could not ensure their effectiveness ${ }^{42}$. Additionally, the previous design of the warning signs for Persian onager did not meet the conventional standards of size, color, direction, and distance to the road. Previously installed warning signs are barely perceptible at night. We propose to install warning lights at the top of each onager warning sign, and to locate the signs at specific locations where crossing was accurately predicted in our models and where high rates of crossing and road kill have been documented.

We also suggest holding educational workshops to increase awareness in parallel to other conservation initiatives. The area has the potential to support tourism for onager watching, which can also bring economic incentives for local communities. We encourage the promotion of ecotourism in our study area. By emphasizing the tourism value of the rural landscapes it can attract visitors from wealthy urban regions and promote awareness and appreciation of conserving the traditional landscapes and wildlife within while bringing in external income to support conservation goals.

We recommend experimenting the involving of local communities in onager monitoring efforts through financial incentives, which may help to track and pinpoint hotspots where conflicts are mostly likely to occur. This would provide information for mitigating road mortality and crop-raids. The key to sustainable onager conservation in wild land-pastoral-agricultural interface requires community-based initiatives. There is a critical need to improve the understanding and appreciation of local communities towards biodiversity in general, and towards onagers in particular, for better ways to manage agricultural activities that can reduce onager damage.

\section{Conclusions}

Human-onager conflict is currently characterized by two important factors: (1) crop-raiding during drought seasons and (2) vehicle collisions. The first step toward implementing mitigation strategies is helping local people protect their lands and initiating compensation through insurance schemes. Another step is to improve road safety for drivers and onagers. Our analysis identified the key habitat, core and movement areas for onagers, and demonstrated that our connectivity analysis predicted highway crossings with great accuracy. Management interventions such as building artificial water ponds, fencing and supplying hay during drought season could also be implemented to reduce onagers entering local's farms. In addition, encouraging ecotourism and educational workshops could help improve understanding and tolerance of onager in the community.

Received: 19 February 2021; Accepted: 2 June 2021

Published online: 14 June 2021 


\section{References}

1. Ziaie, H. A Field Guide to the Mammals of Iran, Iranian Wildlife Center, Tehran (Persian, 2008).

2. Karami, M., Ghadirian, T. \& Faizolahi, K. The atlas of mammals of Iran (Department of the Environment, Tehran, Iran, 2016).

3. Kaczensky, P., Lkhagvasuren, B., Pereladova, O., Hemami, M. \& Bouskila, A. Equus hemionus. The IUCN red list of threatened species 2015. e. T7951A45171204 (2015).

4. Hemami, M.-R. \& Momeni, M. Estimating abundance of the Endangered onager Equus hemionus onager in Qatruiyeh National Park, Iran. Oryx 47, 266-272 (2013).

5. Giotto, N., Gerard, J.-F., Ziv, A., Bouskila, A. \& Bar-David, S. Space-use patterns of the Asiatic wild ass (Equus hemionus): Complementary insights from displacement, recursion movement and habitat selection analyses. PLoS ONE 10, e0143279 (2015).

6. Kanga, E. M., Ogutu, J. O., Piepho, H.-P. \& Olff, H. Hippopotamus and livestock grazing: Influences on riparian vegetation and facilitation of other herbivores in the Mara Region of Kenya. Landsc. Ecol. Eng. 9, 47-58 (2013).

7. Yang, F., Shao, Q. \& Jiang, Z. A population census of large herbivores based on UAV and its effects on Grazing pressure in the yellow-river-source National Park, China. Int. J. Environ. Res. Public Health 16, 4402 (2019).

8. Berger, J. Organizational systems and dominance in feral horses in the Grand Canyon. Behav. Ecol. Sociobiol. 2, 131-146 (1977).

9. Shields, A. V., Larsen, R. T. \& Whiting, J. C. Summer watering patterns of mule deer in the Great Basin Desert, USA: Implications of differential use by individuals and the sexes for management of water resources. Sci. World J. 2012, 2 (2012).

10. Dave, C. V. Understanding conflicts and conservation of Indian wild ass around Little Rann of Kachchh, Gujarat (2010).

11. Rudnick, D. et al. The role of landscape connectivity in planning and implementing conservation and restoration priorities. Issues in Ecol. (2012).

12. Mohammadi, A. et al. Identifying priority core habitats and corridors for effective conservation of brown bears in Iran. Sci. Rep. 11, 1-13 (2021).

13. Adriaensen, F. et al. The application of 'least-cost'modelling as a functional landscape model. Landsc. Urban Plan. 64, 233-247 (2003).

14. McRae, B. H. Isolation by resistance. Evolution 60, 1551-1561 (2006).

15. Cushman, S. A., McKelvey, K. S. \& Schwartz, M. K. Use of empirically derived source-destination models to map regional conservation corridors. Conserv. Biol. 23, 368-376 (2009).

16. Compton, B. W., McGarigal, K., Cushman, S. A. \& Gamble, L. R. A resistant-kernel model of connectivity for amphibians that breed in vernal pools. Conserv. Biol. 21, 788-799 (2007).

17. Panzacchi, M. et al. Predicting the continuum between corridors and barriers to animal movements using Step Selection Functions and Randomized Shortest Paths. J. Anim. Ecol. 85, 32-42 (2016).

18. Cushman, S. A., Lewis, J. S. \& Landguth, E. L. Why did the bear cross the road? Comparing the performance of multiple resistance surfaces and connectivity modeling methods. Diversity 6, 844-854 (2014).

19. Khosravi, R., Hemami, M.-R. \& Cushman, S. A. Multi-scale niche modeling of three sympatric felids of conservation importance in central Iran. Landsc. Ecol. 34, 2451-2467 (2019).

20. Darvishsefat, A. A. Atlas of Protected Areas of Iran (English-Persian) (2006).

21. Ghoddousi, A., Habibi Moghaddam, A., Ashayeri, D. \& Fahimi, H. Status of Asiatic cheetah in Bahram-e-Gour Protected Area. Conserv. Asiat. Cheetah, Final Report, Tehran, Iran (in Persian) (2007).

22. Daniel, W. W. \& Cross, C. L. Biostatistics: A Foundation for Analysis in the Health Sciences (Wiley, 2018).

23. Dimitriadou, E., Hornik, K., Leisch, F., Meyer, D. \& Weingessel, A. Misc functions of the Department of Statistics (e1071), TU Wein. R Packag. 1, 5-24 (2008)

24. Team, R. C. R: a language and environment for statistical computing (R Foundation for Statistical Computing, Vienna, 2018). https:// www.r-project.org/.

25. Fraley, C., Raftery, A. E., Murphy, T. B. \& Scrucca, L. mclust version 4 for R: normal mixture modeling for model-based clustering, classification, and density estimation. (2012).

26. Brown, J. L. SDM toolbox: A python-based GIS toolkit for landscape genetic, biogeographic and species distribution model analyses. Methods Ecol. Evol. 5, 694-700 (2014).

27. Phillips, S. J., Anderson, R. P. \& Schapire, R. E. Maximum entropy modeling of species geographic distributions. Ecol. Modell. 190, 231-259 (2006).

28. Mateo-Sánchez, M. C. et al. Estimating effective landscape distances and movement corridors: Comparison of habitat and genetic data. Ecosphere 6, 1-16 (2015).

29. Phillips, S. J. \& Dudík, M. Modeling of species distributions with Maxent: New extensions and a comprehensive evaluation. Ecography (Cop.) 31, 161-175 (2008).

30. Pearson, R. G., Raxworthy, C. J., Nakamura, M. \& Townsend Peterson, A. Predicting species distributions from small numbers of occurrence records: A test case using cryptic geckos in Madagascar. J. Biogeogr. 34, 102-117 (2007).

31. Naimi, B., Hamm, N. A. S., Groen, T. A., Skidmore, A. K. \& Toxopeus, A. G. Where is positional uncertainty a problem for species distribution modelling?. Ecography (Cop.) 37, 191-203 (2014)

32. Zuur, A. F., Ieno, E. N. \& Elphick, C. S. A protocol for data exploration to avoid common statistical problems. Methods Ecol. Evol. 1, 3-14 (2010).

33. Wan, H. Y., Cushman, S. A. \& Ganey, J. L. Improving habitat and connectivity model predictions with multi-scale resource selection functions from two geographic areas. Landsc. Ecol. 34, 503-519 (2019).

34. Landguth, E. L., Hand, B. K., Glassy, J., Cushman, S. A. \& Sawaya, M. A. UNICOR: A species connectivity and corridor network simulator. Ecography (Cop.) 35, 9-14 (2012).

35. Cushman, S. A., Macdonald, E. A., Landguth, E. L., Malhi, Y. \& Macdonald, D. W. Multiple-scale prediction of forest loss risk across Borneo. Landsc. Ecol. 32, 1581-1598 (2017).

36. Ghoddousi, A. et al. Anthropogenic resistance: Accounting for human behavior in wildlife connectivity planning. One Earth 4, 39-48 (2021).

37. Esmaeili, S., Hemami, M.-R. \& Goheen, J. R. Human dimensions of wildlife conservation in Iran: Assessment of human-wildlife conflict in restoring a wide-ranging endangered species. PLoS ONE 14, e0220702 (2019).

38. Broekhuis, F., Cushman, S. A. \& Elliot, N. B. Identification of human-carnivore conflict hotspots to prioritize mitigation efforts. Ecol. Evol. 7, 10630-10639 (2017).

39. Datiko, D. \& Bekele, A. Conservation challenge: Human-herbivore conflict in Chebera Churchura National Park, Ethiopia. Pak. J. Biol. Sci. 16, 1758-1764 (2013).

40. Linnell, J. D. C., Kaczensky, P. \& Lescureux, N. Human dimensions of wild equid management. Wild Equids Ecol. Manag. Conserv. 121, 2 (2016).

41. Beier, P., Majka, D. R. \& Spencer, W. D. Forks in the road: Choices in procedures for designing wildland linkages. Conserv. Biol. 22, 836-851 (2008).

42. Mohammadi, A. et al. Road expansion: A challenge to conservation of mammals, with particular emphasis on the endangered Asiatic cheetah in Iran. J. Nat. Conserv. 43, 8-18 (2018).

43. Cushman, S. A., Landguth, E. L. \& Flather, C. H. Evaluating population connectivity for species of conservation concern in the American Great Plains. Biodivers. Conserv. 22, 2583-2605 (2013). 


\section{Acknowledgements}

This research has been done under the permission of Fars DoE. This research was supported by the University of Jiroft under the grant Number 4814-99-1. We are grateful for the generous help of Fars province game wardens. We are sincerely thankful to Tanya Rosen, Alistair Bath, and Saloni Bhatia for their valuable edits and comments on the earlier draft.

\section{Author contributions}

A.M. conceptualized and designed the project. A.M., D.N. collected the data. A.M., K.A. analyzed the data and interpreted results. A.M., K.A, D.N. wrote the manuscript with support from H.Y.W., A.A., J.I.R., S.A.C. All authors discussed the results and commented on the manuscript.

\section{Competing interests}

The authors declare no competing interests.

\section{Additional information}

Supplementary Information The online version contains supplementary material available at https://doi.org/ 10.1038/s41598-021-91921-w.

Correspondence and requests for materials should be addressed to A.M.

Reprints and permissions information is available at www.nature.com/reprints.

Publisher's note Springer Nature remains neutral with regard to jurisdictional claims in published maps and institutional affiliations.

(c) (i) Open Access This article is licensed under a Creative Commons Attribution 4.0 International License, which permits use, sharing, adaptation, distribution and reproduction in any medium or format, as long as you give appropriate credit to the original author(s) and the source, provide a link to the Creative Commons licence, and indicate if changes were made. The images or other third party material in this article are included in the article's Creative Commons licence, unless indicated otherwise in a credit line to the material. If material is not included in the article's Creative Commons licence and your intended use is not permitted by statutory regulation or exceeds the permitted use, you will need to obtain permission directly from the copyright holder. To view a copy of this licence, visit http://creativecommons.org/licenses/by/4.0/.

(C) The Author(s) 2021 